\title{
ISO Standards: Impact of Quality Management Systems on Organizational Development
}

\author{
Prof. Dr. Saima Tabassum Siddiqui
}

Assistant Professor (Business Administration), University of Sindh, Jamshoro, Pakistan.

\begin{abstract}
This article reviews the quality management system known as ISO Standards and its impact on organizational development. This paper will be profitable for all the organization's, independent of their area, scale and extent of work. The article evaluates the effect of ISO on the organization's proficiency and recognize the territories for enhancing the general Quality Management System. Since two decades the ISO standards have gained importance in the fielding of managing quality and these trends are indicating good future of ISO certification in Pakistan. The ISO certification facilitates increasing business opportunities for certification bodies, organizations and greater career opportunities for professionals. It also shows commitment to the Quality Management Practices and organizational competitiveness within organizations in Pakistan.
\end{abstract}

Keywords: ISO, Certification, Quality Management System, Organizational Development

\section{INTRODUCTION}

Quality is the relative term subjected to individual and to the organization(Chandrupatla, 2012). Every organization struggles to achieve quality in terms of their goals and outputs. Therefore, there are some criteria set by the organization itself or quality accreditation is obtained from any quality management system. One of this accreditation is ISO certifications. ISO 9000 is one of the well-known premier Quality System Standard published by ISO in the year 1987(Kumar \& Balakrishnan, 2011). The International Organization for Standardization (ISO) is the "quality management standard that presents guidelines intended to increase efficiency of the system"(Muiruri, 2016b) and majority of organizations worldwide follow these guidelines. ISO is the world's biggest, not-revenue driven association to create and issue global administration framework guidelines on various points, for example, the requirements of quality management system (Kumar and Balakrishnan, 2011).

These International Standard represents a worldwide agreement in the issue of quality and standardizations. Its emphasis is on improving organizational effectiveness by improving quality of services and products, customer focus and fulfillment of legal requirements especially for trade (Franceschini, Galetto, \& Cecconi, 2006). Implementation of these standards also bring potential benefits and profits for the organization. Therefore, ISO certification are very famous in developed and underdeveloped countries (Franceschini, et al., 2006). Any ISO 9001 certified organization should ensure a real Quality System to attain maximum customer satisfaction, benefits, workers' motivation, changes and least dismissals and client complaints. In general, the ISO standards create a positive environment for the world in quality products and specifically for the organizational development. They spread knowledge, facilitate trade, disseminate innovative advances in technology, conformity assessment practices and share good management.

\section{HISTORY OF ISO}

In 1906, international Electro Technical Commission (IEC) was formed to set guidelines for electro technical field and later on in 1926 International Federation of the National Standardizing Associations (ISA) was formed for the mechanical engineering. In the year 1946, members of 25 countries decided to develop ISO with an aim to simplify the global harmonization and unification on the industrialized standards and demolished ISA. ISO has 4 major evolutionary phases:

1) Initial Mission: first 40 years were more focused on specific technologies such as measuring sizes of the screws. 
2) In 1980 the process standards for ISO 9000 were explored and developed. This development obsolete the industry- specific nature and it acted as more generalize on all types of industries. ISO 9000 series were adopted by many organizations worldwide and most successful standards.

3) In 1993: ISO took its major step in public policy domain and developed ISO /TC 207 to create ISO 14000 Environmental Management Standards. It involves not only the industry and its direct customers but the extensions indulge the issues of general public.

4) ISO Horizon 2010: Standards of the Sustainable World (ISO 2003) adopted by all the organization to accelerate and for the sustainable development. It encompasses social and environmental domain with statement especially the items and services that go into world trade and that effect on the wellbeing, security, environment and social advance of humanity (ISO, 2016).

\section{Current Trends in Iso}

The World Trade Organization (WTO) recognized ISO outputs as the 'world trade's legal' standards (Morikawa \& Morrison, 2004). Nevertheless, its size and popularity has the major influence on the organizations with biggest organization for developing quality standards. Countries adopting ISO use it not only for international companies but also for the local companies as the market demands. The national governments adopted ISO 9000 and ISO 14000 series standards for procurement criteria. The ISO 9000:1994 focused on quality affirmation by means of preventive activities, rather looking at the last item, and constantly require the confirmation of consistence with the approved systems. ISO 9001:2000 arrangement has consolidated the three models 9001, 9002, and 9003 into one, called 9001. In this arrangement, if an organization includes really taking shape of new items the plan and improvement strategies are required. The 2000 version presented the concept of process management which focused the monitoring and optimizing of a company's activities instead of reviewing their final products. The new ISO 9001:2008 was published on 15 November 2008. However, the ISO 9001:2008 arrangement utilizes an indistinguishable numbering framework from ISO 9001:2000 to sort out the standard.

Therefore, the new ISO 9001:2008 standard looks fundamentally the same as the 9001:2000. There are no new prerequisites included this arrangement. In any case, some essential clarifications and revisions have been made in the arrangement, for example, clarifying the control on outsourced procedures and confirmation of programming, etc.(Kumar and Balakrishnan, 2011).

As of now, 148 nations take an interest in the ISO confederation, 97 as a member, 36 as correspondent members and 15 as supporters (Morrison, 2000).

\section{ISO AND ORgANIZATIONAL DEVELOPMENT}

Quality Management Systems implementation has positive effects on overall organizational performance. Its execution brings about: enhanced quality, worker fulfillment, improved efficiency, representative support, collaboration, correspondence, productivity and more prominent market share. This argument is supported by many studies on the ISO. For example, (Geodhuys \& Sleuwaege, 2013) claimed that the international standard certificate brings efficiency and quality that increases productivity and sales performance. Similarly, (Masakure, Henson, \& Cranfield, 2009) highlight that confirmation to ISO 9000 contributes in building up dependability in the trading environment. Other authors (Terziovski \& Power, 2007; Shafiq, Abid, \& Jalil, 2014) also report substantial impact of ISO 9000 certification on business results as compared to non-certified organizations.

The ISO also contribute towards human resource development. Truss et al(2013) examined the implications of engagement within the context of human resource development (HRD). HRD is concerned with the growth of human and social capital within the society, and there has been growing emphasis in current years on the significance of engagement in improving individual performance and work experience. They highlight the role that HRD can perform not only in rising levels of engagement, but also in reducing levels of disengagement. This can be indicated through organizational development, workplace learning and career development initiatives and one of ISO 900 standard requirements is employees' extensive continuous training on core knowledge of their jobs skills and competency.

ISO is widely used standards due to it applicability in any form of organizations (Geodhuys \& Sleuwaege, 2013). Many organizations report improved customer satisfaction and continual improvement in the organizations is well accounted and documented. The ISO certification also 
enhances the brand image. Internal audit enhances the frameworks and business. There is a reasonable linkage between organization procedure and administration frameworks. Since ISO affirmation, the volume of documentation is streamlined, decreased and underpins the framework well. Administration framework culture has been viably created in accordance with business. Top administration's dedication for the framework is incredible. In human services association such as health care service providers ISO accreditation appropriation of Quality Management Systems had guaranteed consistent preparing and in this manner better execution of wellbeing specialists in their associations (Muiruri, 2016). The total quality management practices in some health care centers in Nairobi, Kenya who distinguished that preparation on Total Quality Management practices would go far in wiping out data asymmetry since its prosperity is very subject to data spread and input over all levels of an association (Muiruri, 2016b). The results in a study by(ul Hassan, Mukhtar, Qureshi, \& Sharif, 2012) also revealed that ISO 9001:2008 certification defines clear responsibilities, and facilitate communication within the higher education and research institutes. It also facilitates in data collection for management regarding the improvement in staff attitude, staff management, and incorporation within the universities and decreases improvisation. A study done by (Mangula, 2013) revealed that the quality of products in manufacturing firms in Tanzania had altogether enhanced after the selection and being certified by ISO 9001. All the more particularly the discoveries portray that quality item had enhanced similarly as diminished customer grievances' and the limit of item to meet the worldwide guidelines. Calisir F, Kulak O, Dogan I (2005) considered components affecting Turkish textile that enhanced after ISO affirmation.

\section{ISO and Organizational Financial Development}

There is a considerable evidence of positive impact of ISO on the financial development of the organization. Research findings done by Oluwatoyin and Oluseun(2009), verify the advantages that accumulate from the usage of Total Quality Management as a key instrument for an association to use in the voyage to remain competitive.

\section{ISO and Organizational Non-Financial Development}

Non-financial benefits controlled by responsibility from top administration, client center, provider relationship, representative inclusion and strengthening, workplace and benchmarking. Malik S.A (2010) reviewed the effect of total quality management system (TQMS) the association's execution and. Moreover, effect of ISO certification on how they implement TQMS and gain non-financial benefits. The study carried out in SME (small and medium enterprise) revealed that ISO-certified industries were more performance oriented than non-ISO certified. Maximum practices of TQM exist in production department and majority was unaware of knowledge about ISO standards and continuous improvement strategies(M. Kamran, 1999; R. Kamran, Alipoor, Moradi, Godarzi, \& Tayeb). However, internal processes are improved by adopting ISO certification revealed by (Cagnazzo L, 2010).Yahiya and Goh (2001) did a review for a specimen of ISO ensured organizations from Singapore, Japan, Korea, Taiwan, Europe, and USA. They presumed that executing ISO 9000 prompted to the ensuing benefits of interest among ensured organizations some of these are: better documentation, more conspicuous quality care, and improved estimation system (Kumar and Balakrishnan, 2011). In the interim, the certified Malaysian association picked up additionally the accompanying external advantages as: enhanced consumer loyalty, higher saw quality, and aggressive edge. In addition, they saw that organizations trading to Europe had more weight to get ISO ensured than others.

\section{ISO in Pakistan}

In the last decade Pakistani organizations showed limited engagement of ISO certification in different business sectors(Anjum \& Imranullah, 2016). Pakistan is far behind in implementation of ISO and quality management practices when comparing with developed countries. It is noted by the (Anjum \& Imranullah, 2016) that Pakistan has a minimal share in ISO certifications, it is currently less than $0.3 \%$ from 2004 to 2014 and there are more than ten business sectors with least number of ISO certifications. The Government of Pakistan had launched an incentive scheme in 2014 for the Small and Medium Enterprises to obtain ISO certification. Under this scheme the organization receives financial support for adoption and implementation ISO certifications and improvement of quality of products and services to comply with the international trade requirements to ensure sustainable \& inclusive business growth. 


\section{Challenges in Iso Application}

There are challenges in the application of the ISO standards. Many organizations hired agencies that provide ISO certification in all these factors. ISO have an advantage for the competitive market. However, these guidelines being flexible can be misused and certified some non-deserving organizations. Some unofficial and unethical agencies without competent evaluators certified the organizations. Inflation in the market derives the unrecognized agencies to work in low budget. Training of employees is one of the major requirements in ISO certification. Lack of training in job skills and in implementation of ISO guidelines identified as the major challenge. The minimum compliance requirements determined in the 9001 may be realized dependably, as a start to empower the business achieve the genuine "excellence"(Kumar and Balakrishnan, 2011). Barak Michalle, (2011) uncovered the effective correspondence with customers, delegates and accomplices has ended up being trying, despite when coordinated with same social structure. It is fundamental to think about that business, if the partners needs are not recognized, acknowledged and conveyed to them, the business can't thrive on long time, paying little respect to ISO certification (Kumar and Balakrishnan, 2011).There are some business parts which are not unequivocally specified in the standard 9001.Some researchers found insufficient knowledge, lack of performance measures and employer commitment were also the hurdles faced by organizations in the context of Pakistan. Tzelepis et al.,(2006) presumed that the general ISO's impacts on administrative ineffectiveness are negative showing that the appropriation of ISO lessens administrative futility.

\section{Conclusion}

This paper studied impacts of ISO on the organizational development and provides prove that affirmation to ISO 9000 is straightforwardly connected with the accomplishment of business results and human asset advancement. This has been studied and verified by different authors earlier like (Anjum \& Imranullah, 2016; Franceschini, Galetto, \& Cecconi, 2006; Geodhuys \& Sleuwaege, 2013; Kumar \& Balakrishnan, 2011; Masakure, Henson, \& Cranfield, 2009; Shafiq, Abid, \& Jalil, 2014; Terziovski \& Power, 2007). This supports the idea of ISO that certification to ISO 9000 leads organizations to higher levels of performance. Similarly (Geodhuys \& Sleuwaege, 2013) found an evidence that International Standardization Certificates raises effectiveness increasingly and prompts to a superior deals execution by firms in nations where marketing and advertising support establishments are powerless.

As majority of the studies from different country and organizational context supports the findings of this paper thus universality of ISO 9000 is established. Certification to ISO 9000 affirmation to ISO 9000 decidedly enhance the dependability and picture of associations in the markets globally and locally, which may profit in expanding the general deals and benefits. Similarly, smooth organizational processes with less waste helps the organizations to develop and improve their effectiveness.

\section{REFERENCES}

Anjum, M. N., \& Imranullah. (2016). ISO Certifications: Trends \& Scope in Pakistan. European Journal of Business and Management, 81-89.

Cagnazzo L, T. P., Fuiano F (2010). Benefits, barriers and pitfalls coming from the ISO 9000 implementation: the impact on business performances. Wseas Trans. Bus. Econ., 7(4): 311-321

Calisir, F., Kulak, O., \& Dogan, I. (2005). Factors influencing Turkish textile companies' satisfaction with ISO 9000. Total quality management \& Business excellence, 16(10), 1193-1204.

Chandrupatla, T. (2012). Quality Concepts - Assets -Cambridge. Cambridge University Press.

Franceschini, F., Galetto, M., \& Cecconi, P. (2006). A worldwide analysis of ISO 9000 standard diffusion: Considerations and future development. Benchmarking: an international journal, 523531.

Geodhuys, M., \& Sleuwaege, L. (2013). The Impact of International Standards Certification on the Performance of Firms in Less Developed Countries. World Development.

ISO. (2016). Retrieved from: http://www.iso.org/iso/sustainable_development, Accessed on [15-122016]

Kamran, R., Alipoor, F., Moradi, R., Godarzi, M., \& Tayeb, j. Survey in role TQM implementation in organizations.

Kamran, M.(1999). Dissertation, Quality Culture in Pakistani Organizations, Sheffield Hall am University, UK. 
Kumar, D. A., \& Balakrishnan, D. (2011). A Study on ISO 9001 Quality Management System Certifications-Reasons behind the Failure of ISO Certified Organizations. Global Journal of Management and Buisness Research, 42-50.

Malik, S. A., Iqbal, M.Z. Shaukat, . (2010). TQM Practices \& Organizational Performance: Evidence From Pakistani SMEs. International Journal of Engineering \& Technology IJET-IJENS Vol:10 No:04 20106504-2727

Mangula, M. S. (2013). Effect Of Quality Management Systems (ISO 9001) Certification On Organizational Performance In Tanzania: A Case Of Manufacturing Industries In Morogoro. International Journal of Technology Enhancements and Emerging Engineering Research, 1(1), 14-19.

Masakure, O., Henson, S., \& Cranfield, J. (2009). Standards and export performance in developing countries: Evidence from Pakistan. The Journal of International Trade \& Economic Develop ment, 395-419.

Morrison, e. a. (2000). Managing a Better Environment: Opportunities and Obstacles for ISO 14001 in Public Policy and Commerce. Pacific Institute. Oakland, California.

Muiruri, Z. K. (2016). Quality Management Systems and Organizational Performance: A Theoretical Review in Kenya's Public Sector Organizations. Science Journal of Business and Management. Vol. 4, No. 5, 2016, pp. 150-155. doi: 10.11648/j.sjbm.20160405.12

Oluwatoyin, A., \& Olusuen, A. (2009). TOTAL QUALITY MANAGEMENT: A Test of the Effect of TQM on Performance and Stakeholder Satisfaction.

Pal, R., Torstensson, H., \& Mattila, H. (2014). Antecedents of organizational resilience in economic crises - an empirical study of Swedish textile and clothing SMEs. International Journal of Production Economics, 147, 410-428.

Shafiq, M., Abid, k., \& Jalil, F. (2014). Perception of managers about the relationship of iso 9000 certification with business results. Journal of Quality and Technology Management, 93-104.

Terziovski, M., \& Power, D. (2007). Increasing ISO 9000 certification benefits: a continuous improvement approach. International Journal of Quality \& Reliability Management, 141-163.

Travis, D. J., Gomez, R. J., \& Barak, M. E. M. (2011). Speaking up and stepping back: Examining the link between employee voice and job neglect. Children and Youth Services Review, 33(10), 1831-1841.

Truss, C., Shantz, A., Soane, E., Alfes, K., \& Delbridge, R. (2013). Employee engagement, organisational performance and individual well-being: exploring the evidence, developing the theory. The International Journal of Human Resource Management, 24(14), 2657-2669.

Tzelepis, D., Tsekouras, K., Skuras, D., \& Dimara, E. (2006). The effects of ISO 9001 on firms' productive efficiency. International Journal of Operations \& Production Management, 26(10), 1146-1165.

ul Hassan, M., Mukhtar, A., Qureshi, S. U., \& Sharif, S. (2012). Impact of TQM practices on firm's performance of Pakistan's manufacturing organizations. International Journal of Academic Research in Business and Social Sciences, 2(10), 232.

Yahya S, \& Goh W. (2001). "The implementation of ISO 9000 quality system”,. International Journal of Quality Reliable manage.18(9):941-966.

\section{AUTHOR'S BIOGRAPHY}

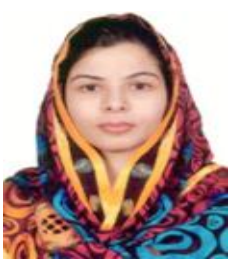

Prof. Dr. Saima Tabassum Siddiqui, started her career as Lecturer (Business Administration) at University of Sindh, Jamshoro, Pakistan in 2007 and presently working there as Assistant Professor (Business Administration). She has 10 plus years' teaching and research experience at University level. She has acquired professional degrees from both public sector and private sector universities recognized worldwide i.e Ph.D (Public Administration) from University of Karachi,

Karachi, Pakistan, MS (Business Administration) from Hamdard University, Karachi, Pakistan, MBA (Finance) and BBA (Honours) from Institute of Business Administration, University of Sindh, Jamshoro, Pakistan. Six research papers are at her credit duly published in well reputed / indexed International Journals with good Impact Factor. 